\title{
Melatonin can induce year-round ovarian cyclicity in red deer (Cervus elaphus)
}

\author{
C. L. Adam, C. E. Moir and P. Shiach \\ Rowett Research Institute, Bucksburn, Aberdeen AB2 9SB, UK
}

\begin{abstract}
Summary. From 17 February 1987 (Day 1) to 5 June 1988 (Day 475), 6 red deer hinds which had been in natural daylength $(\mathrm{NL} / \mathrm{M})$ and 6 hinds which had been in continuous artificial light for the previous month (CL/M) were each given melatonin $(5 \mathrm{mg}$ in feed) daily at 15:00 h. Six controls (C) received unsupplemented feed. From Day 1 all hinds were in natural daylight and ovarian cyclicity was assessed from plasma progesterone concentrations. Group C first went into anoestrus on 15 March 1987 (Day $27 \pm 9 \cdot 2$ (s.e.m)), recommenced cyclicity on 23 October (Day $249 \pm 2 \cdot 3$ ) and went into anoestrus again on 2 April 1988 (Day $411 \pm 8 \cdot 7$ ). Group CL/M first went into anoestrus 31 days earlier $(P<0.05)$ on 12 February (Day $-4 \pm 7.8$ ), before the start of melatonin treatment; 4 hinds then recommenced ovarian cycles 132 days earlier $(P<0.001)$ on 13 June (Day $117 \pm 5.8)$ and continued to cycle for a longer period than did controls. Group NL/M hinds were cyclic at the start of melatonin feeding and continued to cycle for 1 year or more $(\mathrm{N}=6)$. Plasma prolactin concentrations remained suppressed $(<20 \mathrm{ng} / \mathrm{ml})$ for the duration of melatonin-feeding (Groups $\mathrm{CL} / \mathrm{M}$ and $\mathrm{NL} / \mathrm{M}$ ) whereas control values (Group C) were elevated $(20-120 \mathrm{ng} / \mathrm{ml}$ ) between April and August $(P<0.05)$.

The ovarian response by hinds to melatonin therefore depends on initial reproductive status and recent photoperiodic history, and continued administration to cyclic hinds stimulates prolonged ovarian cyclicity irrespective of the time of year.
\end{abstract}

Keywords: red deer; melatonin; progesterone; ovarian cyclicity; out-of-season breeding; prolactin

\section{Introduction}

The red deer hind is a seasonal breeder and, if conception does not occur, oestrous cycles continue from October until as late as March (Guinness et al., 1971). It is now well established that melatonin given orally over a protracted period starting in May or June advances the onset of the breeding season by 5 weeks (Adam \& Atkinson, 1984; Adam et al., 1986, 1989) and also inhibits prolactin secretion in the summer months (Adam et al., 1987, 1989). The response to melatonin treatment initiated earlier in the year is not known. Whereas some data from the ewe, another 'short-day breeder', suggest that early (spring) melatonin treatments can significantly advance the onset of oestrus in the anoestrous ewe (Wigzell et al., 1986; Wallace et al., 1988), other workers report no advance (Nowak \& Rodway, 1985; English et al., 1986), except in ewes in which breeding activity had been artificially advanced the previous season (Symons et al., 1987), and attribute this failure to insufficient prior exposure to long days (Foster, 1983). Moreover, Chemineau et al. (1986) have shown that the stimulatory effect of melatonin treatment on breeding activity in the out-of-season goat is enhanced by prior exposure to long days. However, if melatonin administration commences before the end of the previous breeding season, the onset of anoestrus in the ewe is delayed by 6 weeks (Nett \& Niswender, 1982). 
Although melatonin administration initiated in spring, unlike administration in summer, apparently does not suppress the summer rise in prolactin secretion in the ewe (Poulton et al., 1986), there are no published data for the red deer.

In the present study we investigated the effects of feeding melatonin daily from February onwards on ovarian activity late in the natural breeding season, on the onset and duration of the next breeding season and on seasonal plasma prolactin concentrations in red deer hinds previously kept in natural daylength or exposed for 1 month to continuous light.

\section{Materials and Methods}

Animals and treatments. Eighteen non-pregnant red deer hinds, average live-weight \pm s.e.m. $88 \pm 1.4 \mathrm{~kg}$ and aged 4-8 years, were used for the trial at Duthie Farm, Aberdeen $\left(57^{\circ} \mathrm{N}\right)$. On 19 January 1987 (Day -28$), 6$ hinds were housed in continuous artificial light (approximately 350 lux at deer's eye level) and 12 hinds remained in natural lighting. From 16 February 1987 (Day 0) all hinds were housed in natural daylight away from the sight, sound and smell of a male. They were offered to appetite a complete loose-mix diet with a small ration of pelleted concentrates in the afternoon. From 17 February (Day 1) until 5 June 1988 (Day 475) the 6 hinds which had been in continuous light (Group CL/M) and 6 hinds which had been in natural light (Group NL/M) each received daily $5 \mathrm{mg}$ melatonin (Sigma, Poole, Dorset, UK) in a single feed pellet given at 15:00 h immediately before the afternoon feed. Six control hinds (Group C) received unsupplemented feed throughout.

Blood sampling. Blood samples were taken from all hinds twice weekly on Tuesdays and Fridays throughout the trial. The samples were collected into heparinized vacutainer tubes by jugular venepuncture between 09:00 and 10: $00 \mathrm{~h}$, and the plasma was stored at $-20^{\circ} \mathrm{C}$ until required for assay.

Progesterone assay. Progesterone concentrations in plasma were determined by radioimmunoassay as described previously (Adam \& Atkinson, 1984; Adam et al., 1986). The sensitivity of the assay was $0.2 \mathrm{ng} / \mathrm{ml}$, and intra- and inter-assay coefficients of variation at $1.3 \mathrm{ng} / \mathrm{ml}$ were 9 and $13 \%$ respectively.

Prolactin assay. Prolactin concentrations in plasma were determined by radioimmunoassay as described previously (Adam et al., 1987, 1989). The sensitivity of the assay was $2 \mathrm{ng} / \mathrm{ml}$, and intra- and inter-assay coefficients of variation at $23.8 \mathrm{ng} / \mathrm{ml}$ were 8 and $13 \%$ respectively.

Oestrus. All dates were noted when oestrous behaviour was observed, i.e. when a hind did some or all of the following: rubbed deliberately against or attempted to mount the human observer; stood still, wagged the tail and discharged mucus from the vulva in response to pressure applied to her rump. It was anticipated that a proportion of episodes of oestrous behaviour would pass undetected since many hinds do not display overtly to the human observer, especially in the absence of a stag (C. L. Adam, C. E. Moir \& P. Shiach, unpublished data).

Statistical analysis. Values are given as mean \pm s.e.m., when appropriate, and the statistical significance of differences between group means was assessed by Student's $t$ test.

\section{Results}

Individual plasma progesterone data are shown in Fig. 1. Progesterone values consistently below I $\mathrm{ng} / \mathrm{ml}$ were characteristic of anoestrus, and ovarian activity was judged to be present when concentrations showed cyclic increases from basal levels to values above at least $1 \mathrm{ng} / \mathrm{ml}$ on 2 or more successive sampling dates (Adam et al., 1985)

At the outset of the pretreatment period in January 1987 all hinds were cyclic. Controls (Group C) went into anoestrus on a mean date of 15 March (Day $27 \pm 9 \cdot 2$ (s.e.m.)), 31 days later $(P<0.05)$ than the mean date for Group $\mathrm{CL} / \mathrm{M}$ on 12 February (Day $-4 \pm 7 \cdot 8$ ). Ovarian cycles of the next breeding season for Group C started on 23 October 1987 (Day $249 \pm 2.3$ ) and continued to 2 April 1988 (Day $411 \pm 8 \cdot 7$ ). For 4 hinds in Group CL/M, ovarian cyclicity started 132 days earlier $(P<0.001)$ on 13 June 1987 (Day $117 \pm 5.8)$ and either ceased earlier than in controls in 1988 (Hinds 14 and 16 (Fig. 1) in January and February) or remained cyclic at the end of the trial in June (Hinds 13 and 17). Of the remaining 2 hinds in Group CL/M, one showed ovarian cycles only at the same time as control hinds (Hind 15) and one showed no further ovarian activity before the end of the trial (Hind 18). 


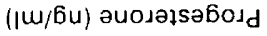

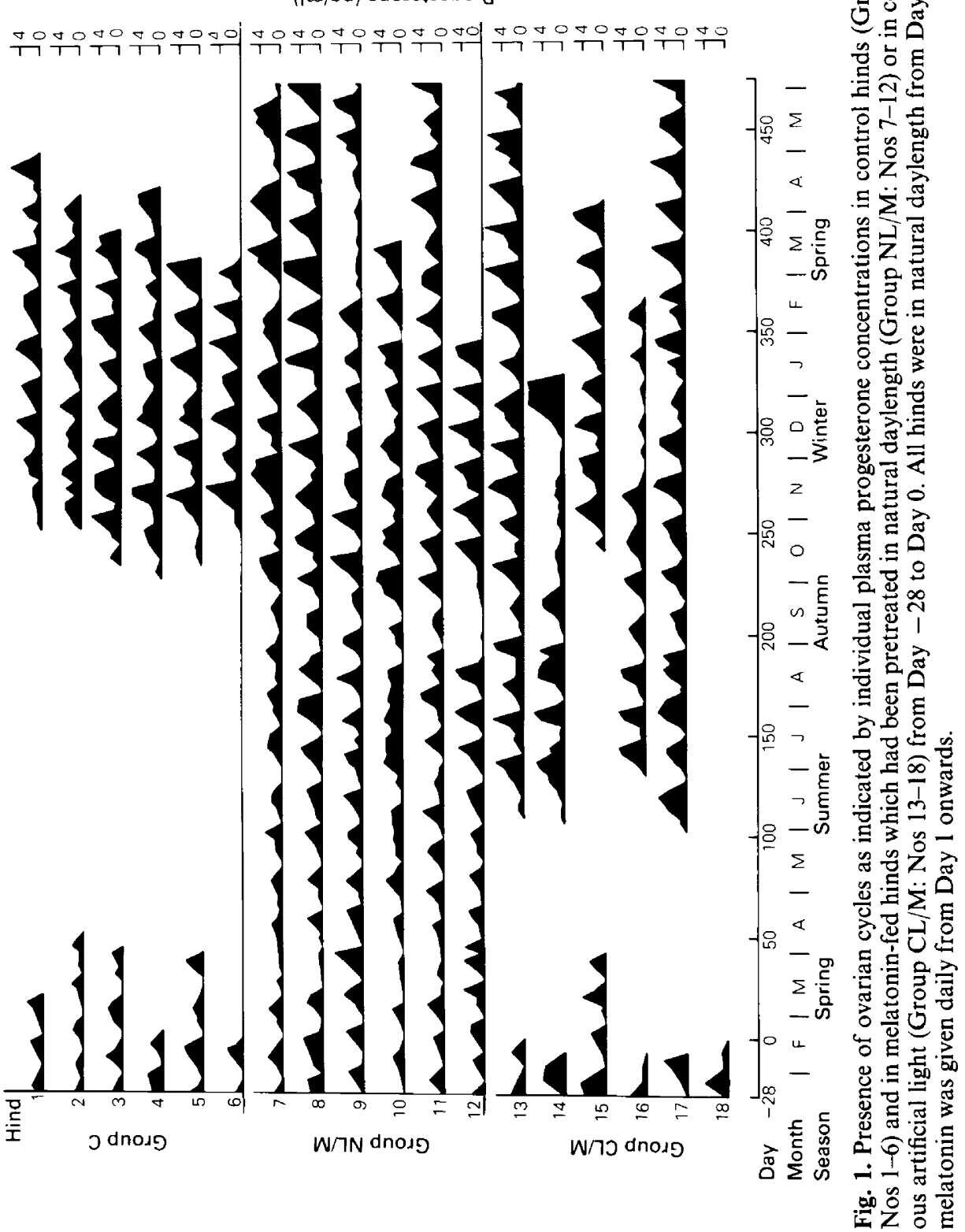


All Group NL/M hinds continued to show ovarian cyclicity throughout 1987. Four remained cyclic at the end of the trial and two went into anoestrus in January and March 1988 (Hinds 12 and 10 , respectively).

The mean length ( \pm s.e.m.) of ovarian cycles, measured between appropriate nadirs in plasma progestrone concentrations, was lower for Group $C(n=60)$ at $19 \pm 0.79$ days than for Group $\mathrm{NL} / \mathrm{M}(n=120)$ at $21 \pm 0.35$ days $(P<0.05)$ and Group CL/M $(n=60)$ at $22 \pm 0.43$ days $(P<0 \cdot 01)$.

Oestrous behaviour was noted, concomitant with low $(<1 \mathrm{ng} / \mathrm{ml})$ plasma progesterone concentrations, in 3 Group $\mathrm{C}$ hinds (Nos 3, 4, and 6 (Fig. 1)) collectively on 14 occasions during the October-March breeding season; in 2 Group CL/M hinds (Nos 13 and 17) on 16 occasions, with 7 during the April-September 'anoestrous' period; and in all 6 Group NL/M hinds on a total of 63 occasions, with 31 occurring in the April-September 'anoestrus'. Hind 11 (Group NL/M) showed oestrus consistently at approximately 19-day intervals throughout the trial, corresponding to all 25 occasions when her plasma progesterone concentrations dropped to basal values.

Group mean plasma prolactin concentrations are given in Fig. 2. Although concentrations for Group CL/M were slightly higher than those for both other groups between Days -7 and 21 $(P>0.05$, non-significant), values remained suppressed below $20 \mathrm{ng} / \mathrm{ml}$ at all times in hinds in Groups $\mathrm{CL} / \mathrm{M}(\mathrm{N}=5)$ and $\mathrm{NL} / \mathrm{M}(\mathrm{N}=6)$. In contrast, Group $\mathrm{C}$ hinds showed significantly elevated values $(P<0.05)$ between Days 52 and 190 (9 April to 25 August 1987) and after Day 421 (12 April to end of trial, 1988). Prolactin values for Hind 18 have been excluded from the Group $\mathrm{CL} / \mathrm{M}$ mean since they were uncharacteristically high, showing frequent surges above the base-line values shown by all other members of the group (Fig. 2); this hind was also uncharacteristically reproductively inactive (Fig. 1) for the duration of melatonin administration.

\section{Discussion}

Untreated red deer hinds in the present trial showed the characteristic period of anoestrus from April to September and a period of ovarian cyclicity from October to March. Feeding melatonin daily for 16 months starting in February prevented the normal transition to anoestrus in the spring in cyclic hinds and induced continued cyclicity for periods of 1 year or more. In hinds which had been induced into premature anoestrus by exposing them to a period of continuous light, such melatonin treatment could both advance by several months the onset of the next breeding season (June) and increase its duration up to 1 year or more.

The effects of continued daily administration of melatonin on the ovarian activity of cyclic red deer have not previously been recorded since administration of melatonin to anoestrous hinds in the summer has ceased once seasonal breeding activity has been initiated and conceptions have occurred (Adam \& Atkinson, 1984; Webster \& Barrell, 1985; Adam et al., 1986). The prolonged stimulatory effect of melatonin on ovarian cyclicity in deer in this trial contrasts with its reported effects in sheep. In ewes, melatonin treatment initiated towards the end of the natural breeding season delays the onset of anoestrus by just 6 weeks (Nett \& Niswender, 1982) and ewes given melatonin daily to advance the next onset of oestrous cyclicity subsequently go into anoestrus correspondingly early to give a normal length breeding season under continued melatonin administration (J. J. Robinson, J. M. Wallace \& S. Wigzell, unpublished data). Similarly, short days or melatonin implantation in the short term stimulate testicular activity in rams whereas in the longer term subsequent spontaneous testicular regression occurs (Almeida \& Lincoln, 1982; Lincoln \& Ebling, 1985). These responses are interpreted as the development of refractoriness to the stimulatory photoperiod (melatonin). Indeed, it is postulated that the normal transition from the breeding to anoestrous seasons in the sheep is associated with refractoriness to the stimulatory ambient daylength rather than a direct inhibitory effect of increasing daylength in the early spring (Worthy \& Haresign, 1983; Robinson \& Karsch, 1984). However, this is perhaps unlikely to be the 


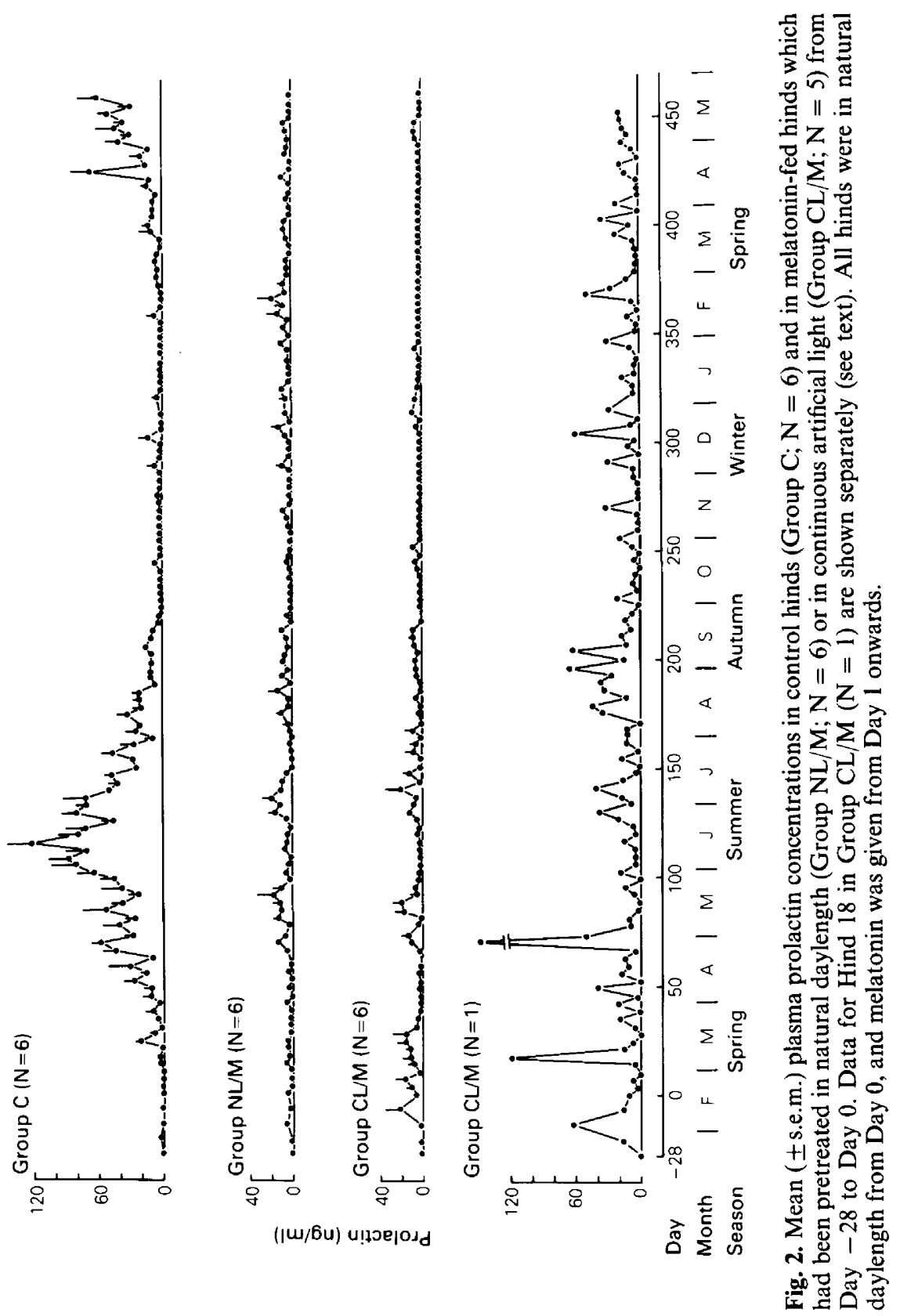


mechanism timing the end of the breeding season in the red deer since this species evidently takes far longer to develop refractoriness to stimulatory melatonin, if at all. (The melatonin treatment protocol employed in the present trial raises daytime plasma melatonin concentrations to physiological nocturnal values, thus presumably conveying a short-day stimulus (C. L. Adam, C. E. Moir \& P. Shiach, unpublished data from a previous trial).) Deer perhaps require a positive inhibitory signal, such as increasing daylength, to stop ovarian cycles in the spring. One month of continuous artificial light ('extra-long' days) in the winter was sufficient to induce premature anoestrus in the present trial, and this was associated with a slight (though not statistically significant) rise in plasma prolactin concentrations.

There was also no evidence of refractoriness to melatonin in terms of prolactin secretion in the deer, since prolactin concentrations remained suppressed for the 475-day duration of melatonin administration. The February-initiated melatonin treatment inhibited prolactin secretion in deer during the long days of summer, in agreement with May- and June-initiated treatments (Adam et al. 1987, 1989). However, in contrast with melatonin-implanted sheep, the melatonin-fed deer showed no spontaneous 'rebound' of plasma prolactin to concentrations greater than control values (Poulton et al., 1987), nor any long-term cyclic changes in prolactin secretion (Lincoln \& Ebling, 1985). Elevated plasma prolactin concentrations coincided with anoestrus in control hinds, and low prolactin values were observed during ovarian cyclicity in all groups. Although prolactin values remained low during anoestrus in hinds in Group $C L / M(N=5)$, it is not clear whether the slight transient rise in prolactin secretion in response to the month in continuous light was responsible for the premature onset of anoestrus. Conversely, pharmacologically-induced hypoprolactinaemia has been shown to delay the onset of anoestrus in hinds (Curlewis et al., 1988). Prolactin may therefore play a more direct role in the timing of the end rather than the start of the breeding season in red deer. Whether this is the case or not, prolactin secretion is evidently extremely sensitive to melatonin and provides a good indication of the animal's perception of daylength. The erratic surges of plasma prolactin throughout the year shown by Hind 18, excluded from the group mean data (Fig. 2), may have indicated a confused perception of photoperiod and perhaps explained why she showed no ovarian activity.

The present results demonstrate that recent photoperiodic history and/or reproductive status dictate the initial response to exogenous melatonin in red deer. Oestrous hinds kept in the natural photoperiod continued to cycle (Group NL/M, N =6) whereas anoestrous hinds that had been kept previously in continuous light started their next breeding season early (Group CL/M, $N=4$ ). Photoperiodic experience is known to be important in determining the reproductive neuroendocrine response to daylength (i.e. melatonin) in the ewe (Robinson \& Karsch, 1984) and goat (Chemineau et al., 1986).

Anoestrus lasted 222 days for controls in the present trial but only 121 days for 4 Group CL/M hinds. The time lag was similar (about 120 days) between the start of melatonin administration in February (present trial) and in May (Adam et al., 1989) until the start of induced breeding activity. Since melatonin is apparently so stimulatory to oestrous hinds, why is there such a delay before anoestrous hinds show a positive breeding response? It is possible that, once initiated, there is a minimum obligatory period of anoestrus while the reproductive axis is reset and before the hind can show ovarian cyclicity again. This period might include a gradual increase followed by a decrease in the 'depth' of anoestrus, such that in February hinds pretreated for 1 month with continuous light and hinds in natural photoperiod in May might effectively be at the same 'depth' and thus show the same time lag in responding to melatonin. Hinds given melatonin from later in the natural anoestrous period, in June, are quicker to show the positive breeding response ( 90 days; Adam et al., 1986).

The 'normality' of the melatonin-induced ovarian cycles has to be considered. Hinds in both treatment groups tended to have longer cycles than did controls in this trial, but the value of $21 \pm 1 \cdot 3$ days is similar to that reported previously for untreated deer (Adam et al., 1985). There was, however, an increased incidence of slightly abnormal progesterone profiles in the treated hinds 
(see Fig. 1), e.g. the occasional 'missed' cycle, and evidence of a persistent corpus luteum from Days 123 to 186 in Hind 10. Furthermore, there was a tendency for peak luteal phase progesterone values to be lower in some Group NL/M hinds during the period equivalent to the normal anoestrus (Fig. 1). Whether these anomalies are significant or not is unclear. Any oestrous behaviour observed was equally intense during 'breeding' and 'non-breeding' seasons, indicating that the out-of-season cycles were normal in this respect. Although oestrus detection was subjective, the same criteria applied to each group and indeed the proportion of overt oestrous periods observed around the time of estimated ovulations was similar in all groups. The fertility of the out-of-season cycles has, of course, yet to be demonstrated.

In conclusion, the response by red deer hinds to melatonin depends on their initial reproductive status and recent photoperiodic history, and continued melatonin administration to cyclic deer, unlike sheep, stimulates prolonged ovarian cyclicity irrespective of the time of year. These findings may provide a further practical use for melatonin in the induction of year-round breeding in farmed red deer.

We thank the staff of the Duthie Farm for assistance in animal management.

\section{References}

Adam, C.L. \& Atkinson, T. (1984) Effect of feeding melatonin to red deer (Cervus elaphus) on the onset of the breeding season. J. Reprod. Fert. 72, 463-466.

Adam, C.L., Moir, C.E. \& Atkinson, T. (1985) Plasma concentrations of progesterone in female red deer (Cervus elaphus) during the breeding season, pregnancy and anoestrus. J. Reprod. Fert. 74, 631-636.

Adam, C.L., Moir, C.E. \& Atkinson, T. (1986) Induction of early breeding in red deer (Cervus elaphus) by melatonin. J. Reprod. Fert. 76, 569-573.

Adam, C.L., Atkinson, T. \& Moir, C.E. (1987) Melatonin lowers plasma prolactin levels in female red deer (Cervus elaphus). J. Pineal Res. 4, 13-20.

Adam, C.L., Moir, C.E. \& Shiach, P. (1989) Plasma prolactin concentrations in barren, pregnant and lactating red deer (Cervus elaphus) given melatonin to advance the next breeding season. Anim. Reprod. Sci. $18,77-86$.

Almeida, O.F.X. \& Lincoln, G.A. (1982) Photoperiodic regulation of reproductive activity in the ram: evidence for the involvement of circadian rhythms in melatonin and prolactin secretion. Biol. Reprod. 27, 1062-1975.

Chemineau, P., Normant, E., Ravault, J.P. \& Thimonier, J. (1986) Induction and persistence of pituitary and ovarian activity in the out-of-season lactating dairy goat after a treatment combining a skeleton photoperiod, melatonin and the male effect. J. Reprod. Fert. 78, 497-504.

Curlewis, J.D., Loudon, A.S.I., Milne, J.A. \& McNeilly, A.S. (1988) Effects of chronic long-acting bromocriptine treatment on liveweight, voluntary food intake, coat growth and breeding season in non-pregnant red deer hinds. J. Endocr. 119, 413-420.

English, J., Poulton, A.L., Arendt, J. \& Symons, A.M. (1986) A comparison of the efficiency of melatonin treatments in advancing oestrus in ewes. $J$. Reprod. Fert. 77, 321-327.

Foster, D.L. (1983) Photoperiod and sexual maturation in the female lamb: early exposure to short days per. turbs oestradiol feedback inhibition of luteinizing hormone secretion and produces abnormal ovarian cycles. Endocrinology 112, 11-17.

Guinness, F., Lincoln, G.A. \& Short, R.V. (1971) The reproductive cycle of the female red deer, Cervus elaphus L. J. Reprod. Fert. 27, 427-438.

Lincoln, G.A. \& Ebling, F.J.P. (1985) Effect of constantrelease implants of melatonin on seasonal cycles in reproduction, prolactin secretion and moulting in rams. J. Reprod. Fert. 73, 241-253.

Nett, T.M. \& Niswender, G.D. (1982) Influence of exogenous melatonin on seasonality of reproduction in sheep. Theriogenology 17, 645-653.

Nowak, R. \& Rodway, R.G. (1985) Effect of intravaginal implants of melatonin on the onset of ovarian activity in adult and prepubertal ewes. $J$. Reprod. Fert. 74, 287-293.

Poulton, A.L., English, J., Symons, A.M. \& Arendt, J. (1986) Effects of various melatonin treatments on plasma prolactin concentrations in the ewe. $J$. Endocr. 108, 287-292.

Poulton, A.L., English, J., Symons, A.M. \& Arendt, J. (1987) Changes in plasma concentrations of $\mathbf{L H}$, FSH and prolactin in ewes receiving melatonin and short-photoperiod treatments to induce early onset of breeding activity. $J$. Endocr. 112, 103-111.

Robinson, J.E. \& Karsch, F.J. (1984) Refractoriness to inductive day lengths terminates the breeding season of the Suffolk ewe. Biol. Reprod. 31, 656-663.

Symons, A.M., Arendt, J., Poulton, A.L. \& English, J. (1987) Induction of early seasonal sensitivity to melatonin in Suffolk-cross ewes. Chronobiol. Int. 4, 219-223.

Wallace, J.M., Robinson, J.J., Wigzell, S. \& Aitken, R.P. (1988) Effect of melatonin on the peripheral concentrations of $\mathrm{LH}$ and progesterone after oestrus and on conception rate in ewes. $J$. Endocr. 119, 523-530.

Webster, J.R. \& Barrell, G.K. (1985) Advancement of reproductive activity, seasonal reduction in prolactin secretion and seasonal pelage changes in pubertal red Downloaded from Bioscientifica.com at 04/26/2023 09:37:51AM 
deer hinds (Cervus elaphus) subjected to artificially shortened daily photoperiod or daily melatonin treatments. J. Reprod. Fert. 73, 255-260.

Wigzell, S., Robinson, J.J., Aitken, R.P. \& McKelvey, W.A.C. (1986) The effect of the oral administration of melatonin at two times of the year on ovarian activity in ewes. Anim. Prod. 42, 448, abstr.
Worthy, K. \& Haresign, W. (1983) Evidence that the onset of seasonal anoestrus in the ewe may be independent of increasing prolactin concentrations and day length. J. Reprod. Fert. 69, 41-48.

Received 20 March 1989 